\title{
Evaluation of Public Acceptability and Longevity of Forced Bloomed Poinsettia (Euphorbia pulcherrima) Pots in Indoor Decorations
}

\author{
D.P. Karunananda and S.E. Peiris ${ }^{1 *}$ \\ Postgraduate institute of Agriculture \\ University of Peradeniya \\ Sri Lanka
}

\begin{abstract}
Production of attractive marketable poinsettia (Euphorbia pulcherrima) pot plants throughout the year can be achieved by forced blooming in the off season, but it is necessary to study their post production conditions and public acceptability prior to marketing. The poinsettia pot plants produced in the off season, when evaluated on its acceptability by the general public through a questionnaire, indicated that $76.6 \%$ of the participants accepted it as a suitable pot plant for indoor decorations in local festivals. In the experiments conducted to evaluate retention of attractiveness of poinsettia under different indoor conditions, mainly at different light levels, it was revealed that leaves, bracts and bract color of these artificially-induced plants remained more than 8 weeks under 1600-4000 lux light level. Almost all leaves and more than $50 \%$ of colorful bracts dropped under the 1-50 lux, and 50-200 lux light levels within the first four weeks while their color reduced to $50 \%$.
\end{abstract}

Keywords: Euphorbia pulcherrima, public acceptability, forced blooming

\section{INTRODUCTION}

Poinsettia (Euphorbia pulcherrima), a popular potted ornamental plant belongs to family Euphorbiacea and is highly sensitive to photoperiod and temperature (Larson et al., 1978). Though the flowers are small and not attractive, the colorful bracts (top leaves) that are present around the flowers in the centre make the plant attractive. In these bracts, accumulation of anthocyanin pigment and arresting of chlorophyll occur with flowering which makes plant colorful (Kannangara \& Hansson, 1998). Since poinsettia responses to photoperiod, short days induce this phenomenon naturally along with the changing from vegetative to reproductive phase. Hence, naturally poinsettia becomes colorful and attractive during November to January. Poinsettia was used for Christmas decorations from the $17^{\text {th }}$ century, because it was regarded as symbolic of the star of Bethlehem. In addition, due to its bright colors and attractive nature, poinsettia is popular around the world as an indoor plant. Northern Asian countries use it to decorate indoors in their festivals from October to December and it is the leader among pot plants in Chinese floriculture markets (Weijie, 2005).

Use of natural flowers and pot plants for indoor decorations is becoming popular in Sri Lanka and many pot plants have already been identified for this purpose. But almost all

\footnotetext{
${ }^{1}$ Department of Crop Science, Faculty of Agriculture, University of Peradeniya, Peradeniya, Sri Lanka

$2^{*} \quad$ Author for correspondence: sriyanip@pdn.ac.lk
} 
selected plants are greenish or closer to green giving less emphasis to indoors in special events. Therefore, there is a need to introduce colourful plants for indoor decorations for special occasions and poinsettia would be a suitable plant for the requirement. Although it is suitable for festival decorations, most of the local festivals and spiritual events fall in the middle part of the year and decorative pot plants are demanding during this period. Hence, when poinsettia is introduced to local floriculture industry, application of early blooming technology is also a necessity. Therefore, in the first part of this experiment production of decorative pot plants was done successfully through early flower induction of vegetative plants by providing artificial short-day conditions (Karunananda \& Peiris, 2009) and consequently the behavior of this forced bloomed poinsettia under indoor conditions and their public acceptability was identified.

Presence of acceptable indoor plant characters such as, long lasting beauty in indoors, resistant to low light and water levels and acceptability by public for indoor decoration are the most important characters that are considered in the introduction of new pot plants to the market. Moreover, the knowledge of after care of poinsettia, color retention/change under different indoor conditions and duration of use should be available for people in the promotion of it as a decorative item.

However, availability of poinsettia pot plants in selected local supermarkets with higher prices during Christmas season indicates that a market for poinsettia has been already created in Sri Lanka. But use of this plant for year round decorations is a new concept; hence the acceptance by public and retention of attractiveness of these forced bloomed plants are needed to be investigated. Therefore, this study was conducted by assessing public acceptability through a questionnaire along with longevity study in order to identify suitability of poinsettia to local festival decorations.

\section{MATERIALS AND METHODS}

\section{Evaluation of consumer acceptability of poinsettia for indoor decorations through a questionnaire}

The experiments were conducted in the Horticulture Research and Development Institute (HORDI), Gannoruwa, Peradeniya during 2008-2009.

Use of poinsettia for year round indoor decorations is a new introduction to Sri Lankan community. Therefore, acceptance of forced blooming and level of acceptance have to be judged before starting a large scale production. Decoration of lobby and indoors using poinsettia pots would be the best way to evaluate the resultant products. Therefore, the information on public acceptability as well as the areas to be improved in the production of poinsettia pots during off-season was gathered using a questionnaire.

The colourful pot plants of poinsettia local line 1101 produced by providing short-day condition of 14 hours night artificially for eight weeks during the off-season (May-June) were used in the experiment (Karunananda \& Peiris, 2009). The response of public on indoor decoration using poinsettia was evaluated through a questionnaire distributed among visitors and staff members of HORDI who belong to different social strata. The entrance and lobby of HORDI and the small house located in the model home garden of HORDI were decorated using the above produced colorful poinsettia pot plants. Decoration was continued for a 
month and the plants were left to become familiar to the people. The questionnaire used to obtain the opinion of the general public on suitability of poinsettia for local festivals or/and for indoor decorations was distributed among the public during the third week of decoration to collect data. In addition appropriateness of used technologies in this study for the production of decorative poinsettia was evaluated through the questions on plant height, shape, shoot number, flower number and bract. Finally, impact of these pots on indoor conditions was also evaluated (Table 1).

Table 1. Questionnaire used to obtain the opinion of the general public on suitability of poinsettia for local festivals or/and for indoor decorations

\begin{tabular}{lll}
\hline No. & \multicolumn{1}{c}{ Question } & Marks 0-10 \\
\hline 01. & Is poinsettia a suitable pot plant for local festival decorations? \\
02. & Are these poinsettia pots suitable for indoor decorations? \\
03. & Has the pruning technique helped to improve attractiveness of plants? \\
04. & Is the shoot orientation suitable for an indoor plant? \\
05. & Is the height of plant suitable for an indoor plant? \\
06. & Does this plant have attractive bush shape? \\
07. & Does the bract have attractive colour? \\
08. & Is this shoot number enough? \\
09. & What is the level of impact of this plant on indoor environment? \\
10. & Do these plants improve the attractiveness of indoor environment? \\
\hline
\end{tabular}

\section{Evaluation of longevity of forced bloomed poinsettia pots under indoor conditions}

The retention of attractiveness of the same forced bloomed poinsettia pot plants under different indoor conditions was also evaluated in this study. Uniform poinsettia plants in the early stage of anthesis and bract colour of all plants of RED GROUP no. 45 A (Royal Horticulture Color chart, 2003) were used for the study. Light levels of 4 different places (indoors) where the plants were kept were 1-50, 50-200, 200-1600 and 1600-4000 lux. The plants were kept in the same place with the same decoration for two months as treatments. Light level (1600-4000 lux) that was used to grow poinsettia in the net house was used as the control.

The treatments were arranged as CRD and the experiment was repeated after three months. Watering of pots was done once/day to wet the medium and fertilization and pest and disease control was not applied during the experiment period.

\section{Data collection and analysis}

Sixty two persons selected randomly took part in the consumer acceptability evaluation study. Ten simple questions were included to the questionnaire (Table 1). The evaluators were required to score within a range of 1 (low acceptance) to 10 (high acceptance) for each question of the questionnaire. The data collected through the questionnaire were tabulated and analyzed using statistical package for social sciences (SPSS).

For the evaluation of longevity of pot plants, light level at the bracts layer was recorded twice a week in every location for each treatment. Number of colourful bracts and number of leaves of each shoot were recorded at weekly intervals. Colour of bracts in each shoot was recorded weekly comparing with Royal Horticulture Colour chart. In assessing colour 
reduction, the initial colours of the bracts were recorded comparing with Royal Horticulture Colour chart (2003) and the initial value was given as 100 . The possible colours that can be obtained through reduction of colours during the experiment period which were identified from preliminary experiments were scored as follows.

\section{Colour}

Red group $\quad 45 \mathrm{~A}$

Red group $\quad 45 \mathrm{C}$

Red group $\quad 45 \mathrm{D}$

Red group $\quad 50 \mathrm{~A}$

Colours deviated from above

\section{Given score}

100

75

50

25

00

The scores given to each color were used to assess the retention of color during the experiment period. The pot plants that retained its color up to $50 \%$ were considered as suitable for use in indoor decorations. The effect of different light levels on bract number, leaf number and bract color was analyzed using statistical package SAS (Statistical analysis system, 2003) and mean comparisons were done using LSD at $\mathrm{P}=0.05$ level.

\section{RESULTS AND DISCUSSION} Evaluation of consumer acceptability of poinsettia for indoor decorations through a
questionnaire

\section{Indoor decoration using poinsettia pots and distribution of questionnaire}

Forty-eight employees of the Department of Agriculture (DOA) and 25 outside people participated in the study. Among them, 21 DOA employees had higher educational qualifications and others had passed at least grade 8. From outside participants, 13 were small-scale flower growers and 12 were general public with interest in floriculture. All participants voluntarily took part in the study and expressed their ideas enthusiastically and independently. However, the following results were obtained by analyzing answers of the questionnaire, which would provide some insight into the public acceptance of poinsettia potted plants for local decorations. The comments of the public could be used in the future modification of poinsettia pot plant production programs.

\section{Suitability of poinsettia for local decorations}

Answers of the first 2 questions (Table 1) of the questionnaire revealed the sustainability of poinsettia as local festival decorations. Table 2 gives the views of each group on suitability of poinsettia for local decorations.

Table 2. View of respondents on suitability of poinsettia for local decorations

\begin{tabular}{lc}
\hline Group & Score (\%) \\
\hline DOA employees & 90 \\
Flower growers & 60 \\
General public & 80 \\
\hline
\end{tabular}


According to the results, the majority of DOA employees and general public have accepted poinsettia for local festival decorations by giving 90 and $80 \%$, respectively. Local floriculture growers also accepted poinsettia for local decorations, but they scored only $60 \%$.

Poinsettia is in the first place of indoor plants in America and Europe (www.ces.ncsu.edu/depts/hort/poinsettia/corrective/a8.html) and traditionally they use it for Christmas decorations. However, poinsettia does not have such religious or historic relation to locals and the only factor that they accept this plant is its attraction. However, a certain number of participants of the study suggested to use poinsettia in local wedding decorations. Though the public has accepted this plant for indoor decorations, the floriculture growers have given comparatively a lower score. The main possible reason is the first two groups consider only the aesthetic appeal but the growers consider about production procedure too. However, all the participants showed interest on poinsettia as a new introduction for indoor decorations.

\section{Applicability of pot plant production techniques}

Answers to $3^{\text {rd }}, 4^{\text {th }}, 5^{\text {th }}$ and $6^{\text {th }}$ questions (Table 1 ) reflect the public acceptability of pruning and height control techniques used in the experiment. When the pruning method was described, the majority of participants accepted that the pruning practice has improved the bushiness of the plant. The average score given by all the participants for the production techniques is $83 \%$. Fig. 1 gives the scores obtained by each production factor emphasized in the questionnaire related to pot plant production. Bushy appearance of the plants was accepted by almost all participants by giving a higher score of $95 \%$ and the lowest score given to plant height was $65 \%$. Personnel communication with the participants pointed out that the plant height should vary with the size, free space and the household items present in the indoor. The suggestion could be used in the future production programs.

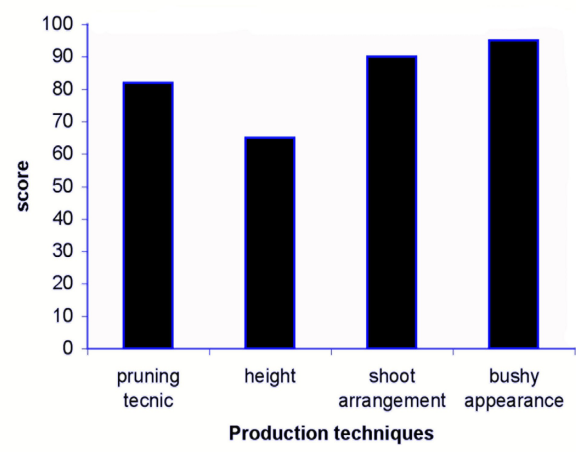

Fig. 1. Public acceptability of production techniques

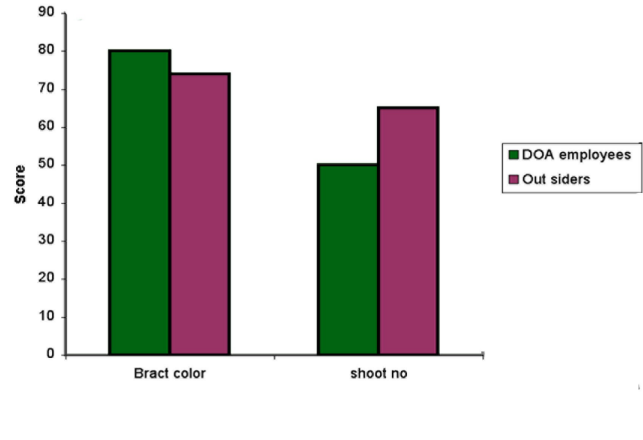

Fig. 2. Acceptability of contribution of flower and bract on attractiveness

\section{Acceptability of flowers and bracts}

The contribution of forced bloomed flowers and bracts on the attractiveness of plants was investigated through questions 7 and 8 (Table 1). Eighty percent score was given to the color of the bracts by DOA employees and $74 \%$ score was given by the outsiders (Fig. 2). Participants belonging to both categories have expected more colorful shoots than what is 
found at present. Outsiders have given $65 \%$ score and DOA officers have given $50 \%$ score for the colorful shoot number (Fig. 2). However, they have indicated that presence of green leaves were also a requirement for pot plant production.

\section{Impact on indoor condition}

Almost all participants of the study have shown positive responses for the last two questions and outsiders have given $95 \%$ score and DOA officers have given $90 \%$ score stating that poinsettia has changed the appearance of indoors. However, all participants of the study emphasized that poinsettia has a very good potential as an indoor plant in Sri Lanka.

\section{Evaluation of longevity of forced bloomed poinsettia pots under indoor conditions}

\section{Effect of indoor light level on leaf and bract number}

A significant leaf drop was observed in the plants kept under light levels 1 and 2 from the $2^{\text {nd }}$ week of experiment and under light levels 1 and 2 , bract abscission was started in the $4^{\text {th }}$ week of experiment. Gradual leaf drop was observed at the light level 3 at $3^{\text {rd }}$ week and bract abscission was not observed throughout the experimental period. Significant leaf or bract drop was not observed in the control plants during the experimental duration, but new green shoots emerged from the top of shoots. Fig. 3 and 4 show the response of green leaves/shoot and bracts/ shoot to each light level in the post-production stage of poinsettia

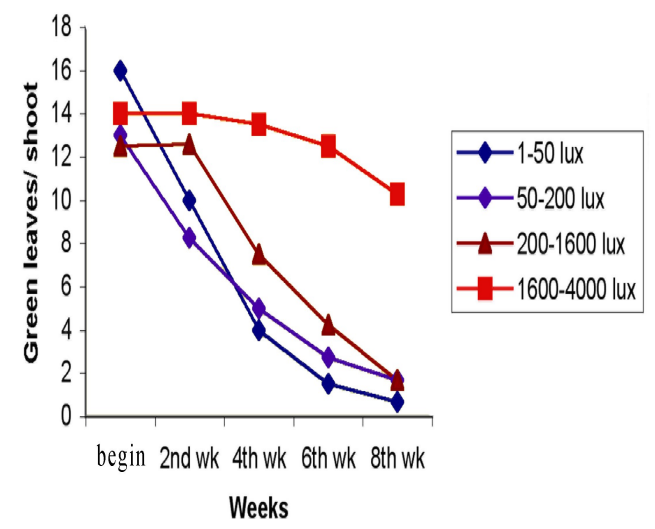

Fig. 3. Green leaves/shoot in respective to each light level in post production stage $(n=18)$

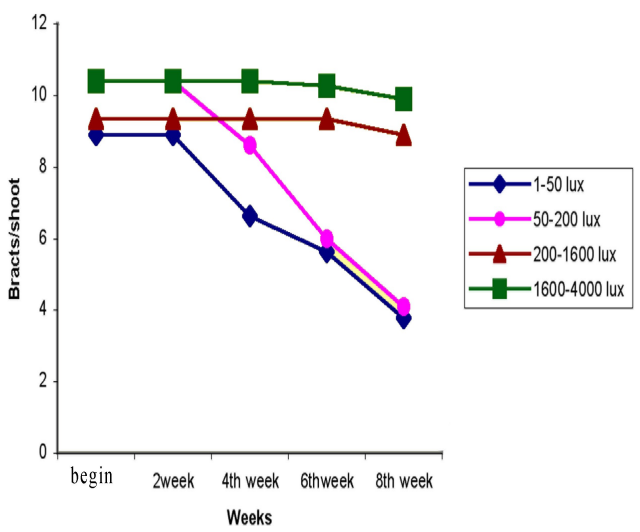

Fig. 4. Colorful bracts/shoot, in respective to each light level in post production stage $(\mathbf{n}=18)$

\section{Effect of light level on bract color}

Since the poinsettia pots in the anthesis stage were used for the study, the bract color of almost all pots was bright red (Red Group 45A). However, with the exposure to different indoor conditions, at different light levels, change of bract color along with leaf and bract drop was observed. The rate of color reduction also varied with the light level of each indoor. Color of poinsettia bracts remained constant for a period of 8 weeks in the control (16004000 lux) and an acceptable bract color was observed even after the completion of experiment at the $8^{\text {th }}$ week. The bract color of plant at light level 3 gradually deviated from the original color and highly varied from acceptable color at the $4^{\text {th }}$ week of experiment. 
The color change of bract is comparatively rapid in plants kept in light levels 1 and 2 where a dramatic color change from the acceptable level was observed at the end of $2^{\text {nd }}$ week of the experiment (Fig. 5). Fig. 6 shows the color score of plant in each shade level during the experiment period.
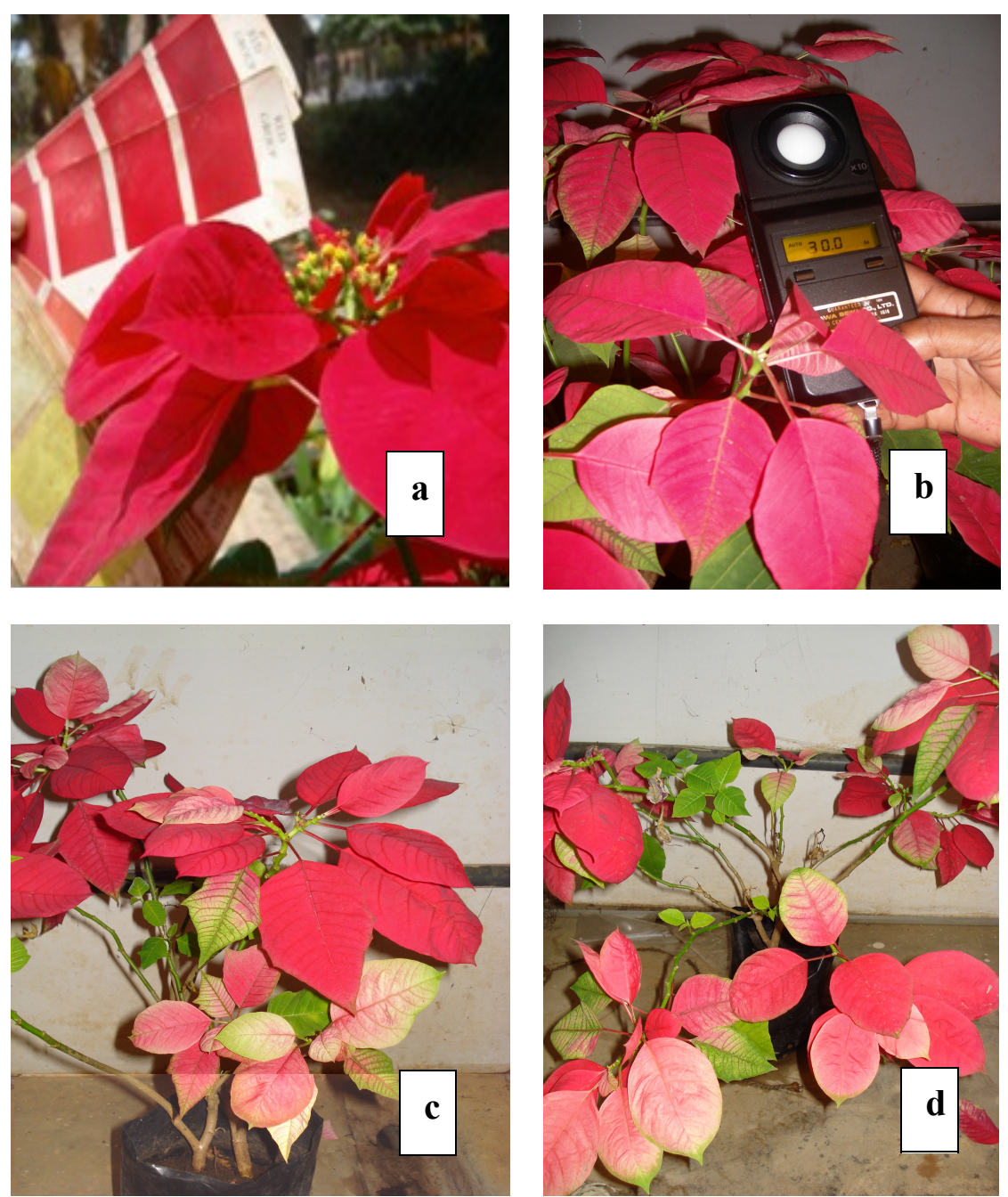

Fig. 5. Poinsettia under low light level (1-50 lux). (a) beginning of the experiment, (b) flower drop in $2^{\text {nd }}$ week (c) color reduction and leaf drop in $4^{\text {th }}$ week (d) color reduction, leaf and bract drop at $6^{\text {th }}$ week while emerging new shoots 


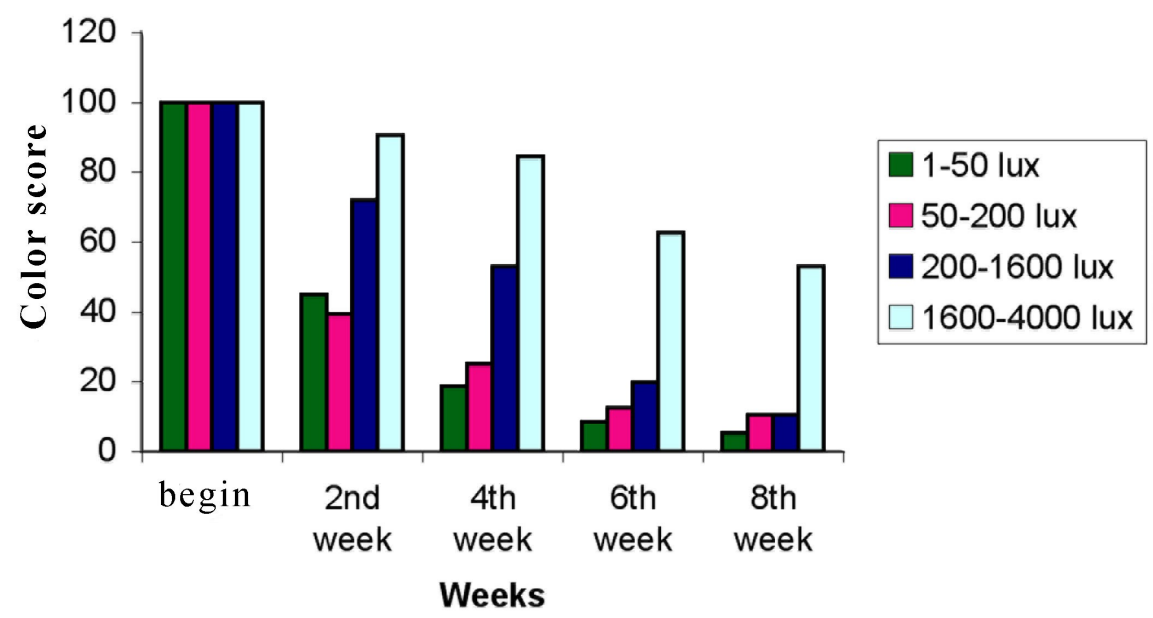

Fig. 6. Color score of poinsettia in each shade level during the experiment period $(n=24)$

According to Staby and Kofranek (1979), not only post-production factors, but also production factors determine the longevity of poinsettia. These factors are the cultivar, fertilizer level, production temperature, light duration and exogenous PGRs etc. Similar to the studies of Leonard et al. (1994) and Shanks et al. (1970), the results of this experiment also showed that low irradiance levels lead to high leaf and bract drop under indoor conditions. Shanks et al. (1970) have shown that there was an interaction effect of photoperiod and light intensity on poinsettia leaf and bract abscission. The leaves and bracts of both cultivars 'Indianapolis Red' and 'Paul Mikkelsen' poinsettias abscised sooner at lower light intensities, higher temperatures and at shorter light durations. According to their results $80 \%$ leaf drop at 80 lux, $75 \%$ leaf drop at 250 lux, $65 \%$ leaf drop at 750 lux and 20 $\%$ leaf drop in 2250 lux have been obtained within 4 week period at $20{ }^{\circ} \mathrm{C}$ and normal day duration in 'Paul Mikkelsen'. As shown in Fig. 3, the same pattern of leaf drop was observed in this experiment where leaf drop is high at low light levels. Unavailability of sufficient light for photosynthesis may be the main reason for this leaf drop. However, Bailey and Miller (1991) stated that low light levels in the last 3 weeks of production period increases leaf retention without giving a clear reason. Additionally they stated that further experiments were necessary to examine the interaction of growth retardant treatments and irradiant levels on photosynthesis.

As shown in the Fig. 6, poinsettia bract color retention for a long period can be obtained at high light levels of indoor than lower light levels. In 1994, Leonard et al. have shown that the interior light level for poinsettia preferably at least 1000 lux and low light levels reduce bract color along with premature flower drop. However, photosynthetic ability of poinsettia bracts is very low compared to green leaves and the accumulated anthocyanin never involve in reaction with light (Woodrow \& Grodzinski, 1987). The observations showed that the color reduction of the bracts of poinsettia under low light levels may be attributed to its attempt to increase the amount of chlorophyll pigments. However, from the results of the present study, it can be concluded that the longevity of indoor poinsettia plants highly depends on the post-production light level (of indoors) and when the light level increases the longevity of plants also increases. 


\section{CONCLUSIONS}

Colorful poinsettia pots produced through forced blooming were accepted by $76.6 \%$ of interviewed public as suitable pot plants for year round indoor decorations. The average score given by all the participants for the production techniques is $83 \%$. All the participants of the study have accepted that the ability of poinsettia changing appearance of indoor by giving higher scores as $95 \%$ by outsiders and $90 \%$ by DOA officers. Attractiveness of the forced bloomed poinsettia retained more than 8 weeks in the higher light level (1600-4000 lux) and reduction of bract color, leaf drop and bract drop were increased at lower light levels.

\section{ACKNOWLEDGEMENT}

Authors would like to acknowledge, Director and Staff of Horticulture Research and Development Institute, Gannoruwa, Peradeniya for their support and encouragement during the study.

\section{REFERENCES}

Bailey, D.A. and Miller, W.B. (1991). Poinsettia Developmental and pot production responses to growth retardants and irradiance. Hortscience 20(12): 1501-1503.

Kannangara, C.G. and Hansson, M. (1998). Arrest of chlorophyll accumulation prior to anthocyanin formation in, Euphorbia pulcherrima. Plant Physiol. Biochem. 36(12) 843-846.

Karunananda, D.P. and Peiris, S.E. (2009). Investigation on effects of pinching, cycocel and B-nine treatments on branching habit of pot poinsettia (Euphorbia pulcherrima Willd). Trop. Agric. Res. 21(3): 284-292.

Larson, R.A., Love, J.W. and Strider, D.L. (1978). Commercial poinsettia production. N.C. Agr. Ext. Ser. Ag-108.

Leonard, R.T., Nell, T. A and Barrett J. (1994). Deliver Poinsettias the consumer will enjoy. The Flori-report -1994-Fall.4-5.

Royal Horticultural Color Chart (2003). Royal Horticulture Society, London.

SAS system (2003). SAS/STAT-9 User's Guide. SAS institute, Cary, NC-USA.

Shanks, J.B.,Nobel, W.E. and Witte, W.T. (1970). Influence of Light and Temperature upon leaf and bract abscission in poinsettia. J. Amer. Soc. Hort. Sci. 95(4): 446-449.

Staby, G.L and Kofranek, A.M. (1979). Production conditions as they affect harvest and post harvest characteristics of Poinsettia. J. Amer. Soc. Hort. Sci. 104(1): 88-92.

Weije, J. (2005). Cultivation of green house crops; Anthurium and Poinsettia. In Hand book for Training Workshop on Cultivation Technology of Ornamental Plants - September 2005. Chinese academy of agriculture, Beijing, China 45-52.

Woodrow, L. and Grodzinski, B. (1987). Ethylene evolution from bracts and leaves of poinsettia, Euphorbia pulcherrima Willd. J. Experimental Bot. 38(197):2024-2032. 
19Karunananda and Peiris

www.ces.ncsu.edu/depts/hort/poinsettia/corrective/a8.html (Accessed on 2009-8-14) 